\title{
Hybrid graphene oxide/DAB-Am-16 dendrimer: Preparation, characterization chemical reactivity and their electrocatalytic detection of L-Dopamine
}

\author{
Devaney Ribeiro Do Carmo*, Daniela Silvestrini Fernandes \\ Faculdade de Engenharia de Ilha Solteira UNESP - Univ. Estadual Paulista, Departamento de Física e Química, Av. Brasil Centro, 56, CEP 15385-000, Ilha \\ Solteira, SP, Brazil
}

\section{A R T I C L E I N F O}

\section{Article history:}

Received 25 May 2017

Received in revised form

1 July 2017

Accepted 5 July 2017

Available online 8 July 2017

\section{Keywords:}

Surfaces

Chemical synthesis

Electrochemical measurements

Photoelectron spectroscopy

Raman spectroscopy

Electrochemical properties

\begin{abstract}
A B S T R A C T
Graphene oxide (GO) was chemically modified with a poly(propylene)imine Generation 3.0 dendrimer (DAB-Am-16). The characterization, structure and properties of hybrid graphene oxide/DAB-Am-16 dendrimer was studied by Raman spectroscopy, Fourier-Transforming Infrared Spectroscopy (FT-IR), XRay Photoelectron Spectroscopic (XPS), X-ray Diffraction (XRD), Scanning Electron Microscopy (SEM) and Thermogravimetric analysis. After functionalized the hybrid material (GOD) can interact with copper and subsequently with hexacyanoferrate (III) ions (GODHCu). The GODHCu incorporated into a graphite paste electrode $(20 \% \mathrm{w} / \mathrm{w})$ was applied to an electrocatalytic detection of neurotransmitter L-dopamine using differential pulse voltammetry. The analytical curve showed a linear response in the concentration range from $1.0 \times 10^{-7}$ to $1.0 \times 10^{-5} \mathrm{~mol} \mathrm{~L}^{-1}$ with a corresponding equation $\mathrm{Y}(\mathrm{A})=1.706 \times 10^{-5}+0.862$ [Ldopamine] and a correlation coefficient $\mathrm{r}^{2}=0.998$. The detection limit was $6.36 \times 10^{-7} \mathrm{~mol} \mathrm{~L}^{-1}$ with a relative standard deviation of $\pm 4 \%(\mathrm{n}=3)$ and an amperometric sensitivity of $0.862 \mathrm{~A} / \mathrm{mol} \mathrm{L}^{-1}$.
\end{abstract}

(c) 2017 Elsevier Masson SAS. All rights reserved.

\section{Introduction}

The sheet of graphite oxide, now called graphene oxide (GO), is the product of the chemical exfoliation of graphite and has been known for more than a century [1,2]. This intriguing material has attracted major interdisciplinary attention due to the wide range of applications envisaged across several scientific and engineering fields including physics, chemistry, biology, and medicine [3-7]. Compared to graphene, graphene oxide has hydroxyl and epoxide groups in the basal plane and carboxyl groups on its exposed edges, its molecular structure [8] also allows for additional supramolecular interactions that can be exploited for various functional applications, including biosensing [9] and drug delivery [10].

The chemical functionalization of the GO is still a subject unexplored and replication new methods to modify the GO are required [11]. The new chemically modified graphene with specific molecular architectures is highly desired in the field of sensors or to change the electronic properties of graphene [12,13]. Among a variety of functionalization methods for graphene based materials,

\footnotetext{
* Corresponding author.

E-mail address: docarmo@dfq.feis.unesp.br (D.R. Do Carmo).
}

the use of reagents containing nitrogen have attracted great attention. Thus, the chemical functionalization, while preserving the carbon backbone, is one of the main challenges for the preparation of new GO-based molecular architectures with a controlled structure, since GO decomposes in water and permanent defects are introduced in an uncontrolled manner by the cleavage of the carbon framework [14].

GO was recently applied to prepare polymer nanocomposite hydrogels with improved mechanical performance compared to conventional hydrogels $[15,16]$ and various self-assembly approaches were used to prepare physically crosslinked GO-polymer nanocomposite hydrogels $[17,18]$. The driving forces to form these hydrogels were physical interactions, including $\pi-\pi$ interaction, hydrogen bonding, electrostatic interaction and coordination [19].

The recent availability of water-soluble graphene oxides (GO) obtained by the acid oxidation of the graphite powder allows graphene functionalization through several reactions in solution [19-21] to be used as a precursor in the production of nanocomposites with better mechanical, thermal and/or electrical properties $[22,23]$ and when modified chemically or electrochemically, it can result in an excellent electrochemical sensor.

Dendrimers are a type of organic molecules which are highly 
branched and monodisperse [24]. Polyamidoamine (PAMAM) dendrimers have been extensively studied in the biomedical field because of their low cytotoxicity, controllable size and ease of functionalization [25].

A wide variety of synthesized dendrimers and their applications are described in many reviews, articles and patents [26-33] in all fields of knowledge. The rigid spheroidal architecture of these molecules leads to several properties such as: low viscosity, high solubility and miscibility, high reactivity in the terminal chains. The combination of dendrimers and graphene oxide was introduced to develop hybrid nanomaterials in different forms. PAMAM is the most commonly used class dendrimer for chemical modification of graphene oxide. The PAMAM-modified GO nanosheets and GO-PAMAM composites, showing an excellent adsorption capacity, they were investigated for the removal of heavy metal ions from wastewater $[34,35]$. Another potentially dendrimer for the chemical modification of graphene is the poly(propylene)imine Generation 3.0 (DAB-Am-16). The DAB-Am-16 also has the ability to chelate many metals [36] in a controlled manner and plays an important biological role because they are used with drugs and others medical applications [31]. The chemical modification of graphene with dendrimers of the two classes above, as well as their physical and chemical aspect, specifically for DAB-Am-16 are very restricted and not much explored.

In this context, chemically modified graphene oxide with DABAm-16 dendrimer (GOD) can serve as a chelator of different metals, such as $\mathrm{Cu}^{2+}$, as well as the matrix for the inclusion of important organic and inorganic molecules of pharmacological interest. In the present work, we synthesize GODHCu composite through two steps: i) an electrostatic interaction of the hexacyanoferrate ion $\left[\mathrm{Fe}(\mathrm{CN})_{6}\right]^{3-}$ with protonated $\mathrm{NH}_{2}$ groups $\left(-\mathrm{NH}_{3}^{+}\right)$ at the chain end of the dendrimer which is not covalent linkage in the graphene oxide surface (GODH). ii) and a subsequent reaction of GODH with copper ions $\left(\mathrm{Cu}^{2+}\right)(\mathrm{OGDHCu})$. As a direct application, GODHCu was tested in the electrocatalysis of neurotransmitter L-dopamine using differential pulse voltammetry (DPV).

\section{Experimental}

\subsection{Reagents and solutions}

Graphene oxide powder (15-20 sheets, 4-10\% edge-oxidized), poly(propylene)imine hexadecaamine dendrimer (DAB-Am-16 (Generation 3.0)), $\mathbf{N}, \boldsymbol{N}^{\prime}$-Dicyclohexylcarbodiimide (DCC), graphite and L-Dopamine were purchased from Aldrich and all other reagents and solvents used in this work were analytical grade (Alpha Aesar, Merck) and were used as received (without further purification). All solutions were prepared using deionized water with resistivity of not less than $18.2 \mathrm{M} \Omega \mathrm{cm}$. L-Dopamine solutions were prepared immediately before use.

\subsection{Functionalization of graphene oxide powder with poly(propylene)imine hexadecaamine dendrimer (GOD)}

GOD powder was functionalized according to the procedure described in the literature [37], with some modifications described as shown in the Scheme (Fig. 1). In a $250 \mathrm{~mL}$ round-bottom flask, $1.0 \mathrm{~g}$ of graphene oxide powder, $0.672 \mathrm{~g}$ of dendrimer and $0.100 \mathrm{~g}$ of: $N, N^{\prime}$-Dicyclohexylcarbodiimide (DCC) (as catalyst) were dissolved in $50 \mathrm{~mL}$ of ethanol, followed by ultrasonication for $10 \mathrm{~min}$. The mixture was then refluxed for $24 \mathrm{~h}$. Once the reaction was completed, the resulting solution was evaporated and the solid product was vacuum filtered through a $0.22 \mu \mathrm{m}$ polyvinylidene difluoride (PVDF) membrane and washed exhaustively with ethanol to remove unreacted dendrimer. The final product (GOD powder) was dried in a vacuum oven $\left(70^{\circ} \mathrm{C}\right)$. The final product yield was $1.171 \mathrm{~g}$.

\subsection{Preparation of chemically modified graphite paste electrodes}

The graphite paste electrodes were prepared by mixing the GOD $(20 \mathrm{mg})$, graphite powder $(80 \mathrm{mg})$ and nujol oil $(25 \mu \mathrm{L})$. The electrode body was fabricated from a glass tube of i.d. $3 \mathrm{~mm}$ and height of $14 \mathrm{~cm}$, containing graphite paste. A copper wire was inserted through the opposite end to establish electrical contact. After the mixture had been homogenized, the modified paste was carefully placed at the tip of the tube avoid possible air gaps, which often enhances electrode resistance. The external surface of the electrode was smoothed on soft paper [38].

\subsection{Characterization measurements}

The Raman spectroscopic measurements were carried out using a HORIBA JOBIN YVON HR800UV Raman spectrometer with He-Ne laser and an Argon ion laser was used for $633 \mathrm{~nm}$ excitation. X-ray photoelectron spectroscopy (XPS) measurements were performed in a UNI-SPECS UHV surface analysis system using $\mathrm{Al} \mathrm{K} \alpha$ radiation $(h v=1486.6 \mathrm{eV})$ and a pass energy of $10 \mathrm{eV}$ for high-resolution spectra. The Casa XPS software was used for the determination of the surface composition and for the deconvolution of the $\mathrm{C} 1 \mathrm{~s} ; \mathrm{O} 1 \mathrm{~s}$; $\mathrm{N}$ 1s spectra using a Shirley baseline and Voigt profiles. The vibrational spectra of the materials were obtained by a Nicolet 5DXB FT-IR spectrometer (Nicolet Instruments, Madison, WI). The pastilles for analysis were prepared using $150 \mathrm{mg}$ of $\mathrm{KBr}$ (previously dried) and $1.5 \mathrm{mg}(1.0 \%(\mathrm{~m} / \mathrm{m}))$ of each sample. A minimum of 64 "scans" with a resolution of $\pm 4 \mathrm{~cm}^{-1}$ in a band of 4000 to $400 \mathrm{~cm}^{-1}$ was used. The X-Ray diffraction characterization was carried out using Rigaku Ultima IV diffractometer with $\mathrm{Cu}$ Ka radiation $\left(\lambda=1.5418 \AA\right.$ ) and $2 \theta$ range between $5^{\circ}$ and $30^{\circ}$. The microstructure was observed using a field-emission scanning electron microscope (FE-SEM, JSM-6700 F, Japan). The thermal analyzes of the samples were carried out using two equipment's - SDT 2960 from TA Instruments and SDT Q600 from TA Instruments. The thermogravimetric curves were obtained using approximately $6 \mathrm{mg}$ samples placed in alumina crucibles and subjected to a controlled air temperature program and nitrogen flow of $100 \mathrm{~mL} \mathrm{~min}^{-1}$, with a heating rate of $10^{\circ} \mathrm{C} \mathrm{min}^{-1}$. The sample analyzes were performed at the room temperature interval up to $1200{ }^{\circ} \mathrm{C}$. Electrochemical Measurements was preformatted using the PALM SENS 3 potentiostat. The three electrode systems used in these studies consisted of a modified working electrode (graphite paste electrode) an Ag/ $\mathrm{AgCl}_{\text {(sat.) }}$ reference electrode, and a platinum wire as the auxiliary electrode. The measurements were carried out at $25^{\circ} \mathrm{C}$.

\section{Results and discussion}

\subsection{Raman spectroscopy}

Raman spectroscopy is a very powerful tool and allows a relatively easy and effective approach to investigate any structural changes resulting from the chemical modification of graphene oxide. However, this technique can provide an important insight into the characterization, considering the fact that the conjugated and double carbon-carbon bonds lead to high Raman intensities [39].

The Raman spectrum of graphene oxide modified with dendrimer (GOD) is shown in Fig. 2(A). The spectrum of GOD displays three prominent bands at 1323 (D band), $1567 \mathrm{~cm}^{-1}$ ( $\mathrm{G}$ band) and 2663 (2D band). In comparison of spectrum of GO (Fig. 2B) only the $D$ band shift to lower wavenumbers $\left(2 \mathrm{~cm}^{-1}\right)$ while the $G$ band is 

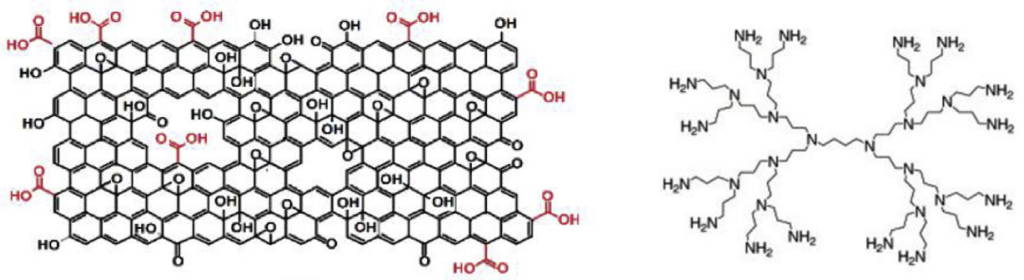

(B)

(A)
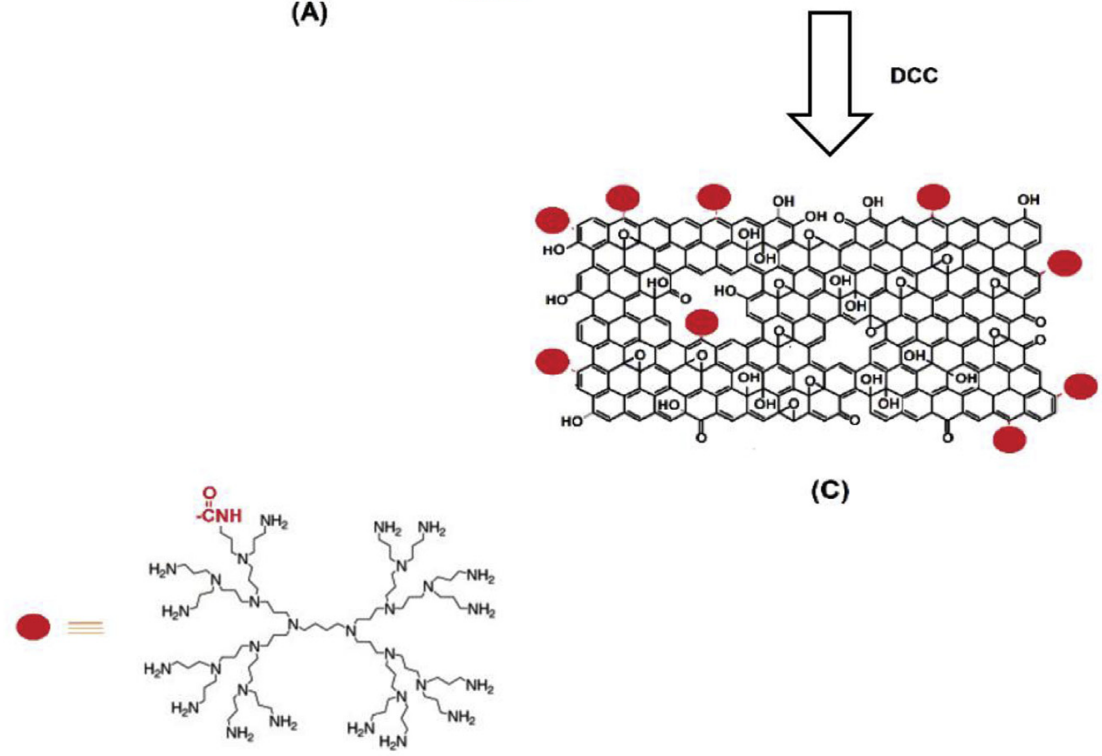

(C)

Fig. 1. Schematic illustration of the functionalization of GO.

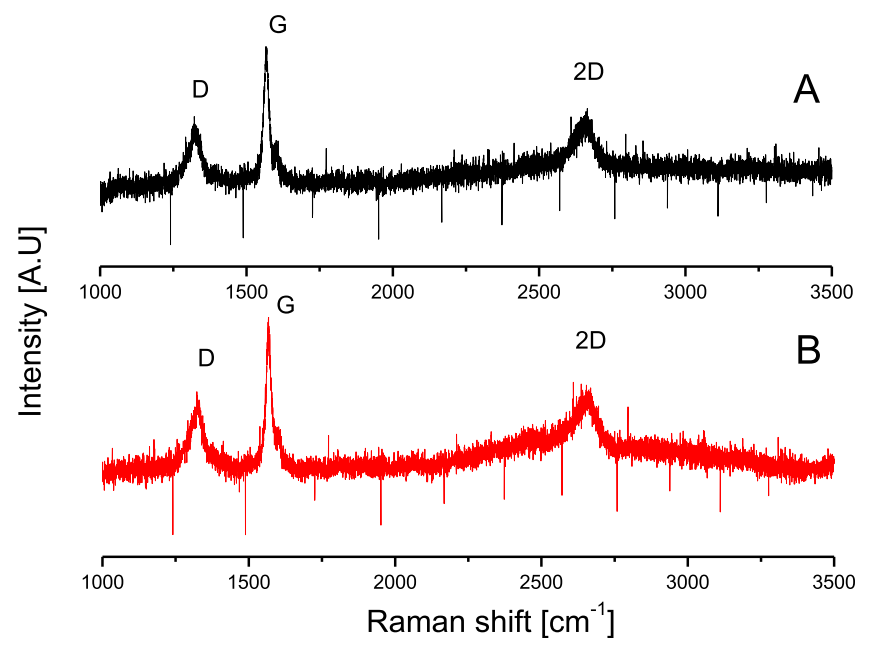

Fig. 2. Raman spectra of: GO (A) and GOD (B).

maintained in same position after functionalization. This displacement was attributed to a structural disorder generated during the surface modification process of graphene oxide. This observation was also verified for surface modification of graphene oxide with polyamidoamine (PAMAM) dendrimer nanocomposites hydrogels [40]. The D and $G$ bands were attributed to the local defects (found at the edges of graphene sheets) and the $s p^{2}$ graphitized structure due to the double degenerated zone center $E_{2 g}$ vibration mode, respectively [41,42].

The intensity ratio $\left(\mathrm{I}_{\mathrm{D}} / \mathrm{I}_{\mathrm{G}}\right)$, known as the Tuinst-Koening (TK) relation assigned to lower defects/disorders [43] increases from GO (0.438) to GOD (0.442), implying an higher degree of lattice disorder and defects in the latter. It is important to make it clear here that graphene oxide has not been synthesized. It was acquired from Sigma and it is in. This may explain the intermediate ID/IG values between graphite and graphene.

The $2 \mathrm{D}$ band in $\mathrm{GO}$ attributed to the respective higher order modes originating from a double resonance process can be affected by a chemically induced defect [42]. After chemical modification, the position of the $2 \mathrm{D}$ peaks shift to lower wavenumber $\left(10 \mathrm{~cm}^{-1}\right)$. The Raman Spectra band positions $I_{D} / I_{G}$ (intensity ratio of $D$ and $G$ bands) values of the GO and GOD are listed in Table 1.

From these results, we conclude that a minimum structural defects were, in a first stage, introduced by the attachment of functional dendrimer groups.

\subsection{X-Ray Photoelectron Spectroscopic (XPS)}

In order to identify all the chemical constituents of GO and GOD, as well as their oxidation states and to gain further insights into surface chemical changes associated with the reaction shown in Scheme (Fig. 1), we have also performed X-Ray Photoelectron Spectroscopic (XPS). The XPS spectra for GO and GOD are shown in Fig. 3(A) and (B) respectively. Table 2 lists the $\mathrm{C}, \mathrm{O}$ and $\mathrm{N}$ atomic percentage values of graphene oxide (GO) and graphene oxide functionalized with dendrimer (GOD) samples obtained from high

Table 1

Raman Spectra band positions $\mathrm{I}_{\mathrm{D}} / \mathrm{I}_{\mathrm{G}}$ (intensity ratio of $\mathrm{D}$ and $\mathrm{G}$ bands) values of the GO and GOD.

\begin{tabular}{lllll}
\hline Sample & D band $\left(\mathrm{cm}^{-1}\right)$ & G band $\left(\mathrm{cm}^{-1}\right)$ & 2D band $\left(\mathrm{cm}^{-1}\right)$ & $\mathrm{I}_{\mathrm{D}} / \mathrm{I}_{\mathrm{G}}$ \\
\hline GO & 1321 & 1567 & 2663 & 0.935 \\
GOD & 1323 & 1567 & 2653 & 0.931 \\
\hline
\end{tabular}



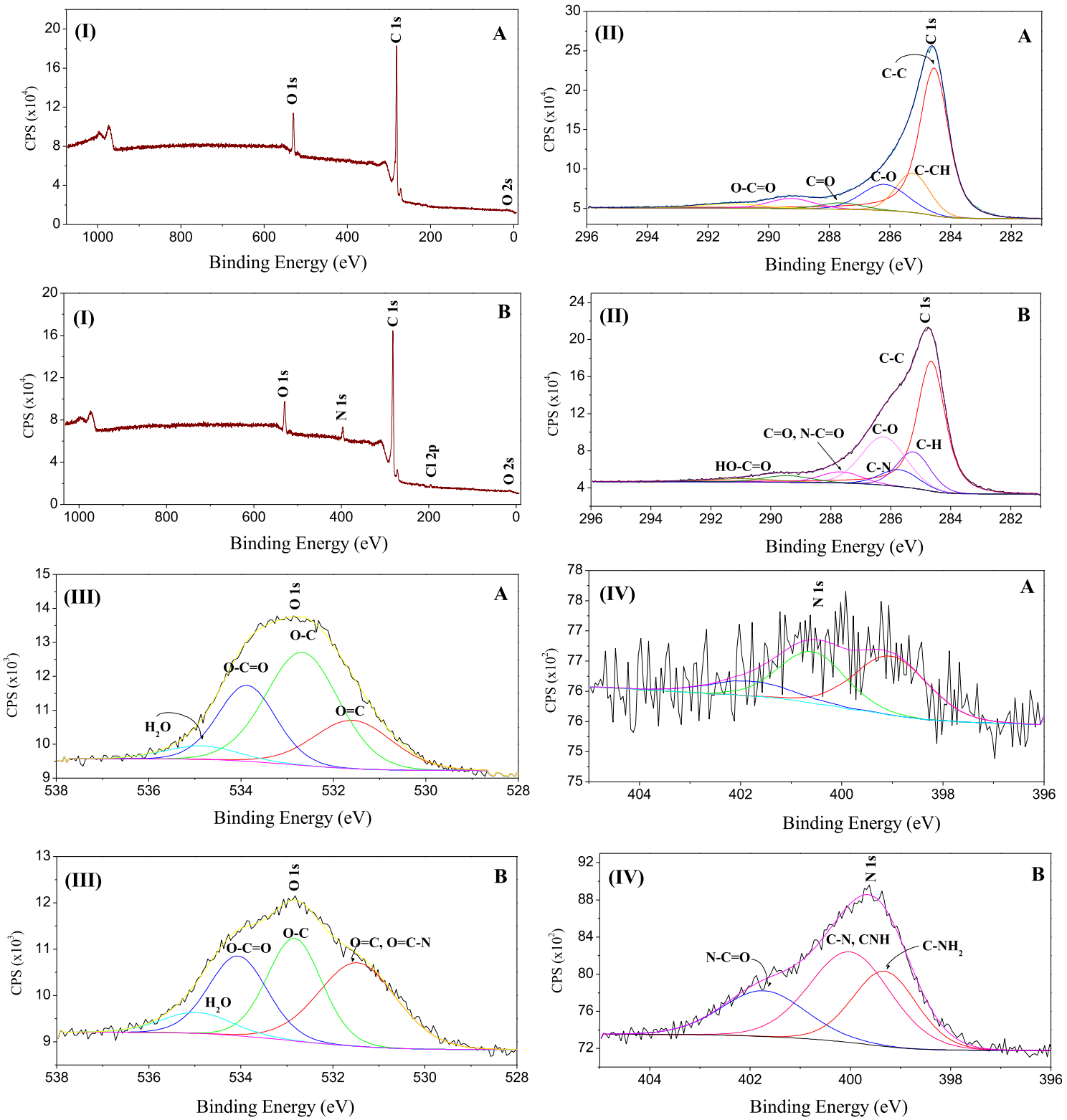

Fig. 3. XPS of GO (A) and GOD (B): (I) Full range, (II) high resolution C 1s, (III) high resolution O 1s, (IV) high resolution N 1 s.

Table 2

Atomic percentage of GO and GOD elements constituents.

\begin{tabular}{lll}
\hline Elements & ${\text { [Atomic \% }]^{\mathrm{a}}}$ & \\
\cline { 2 - 3 } & $\mathrm{GO}$ & $\mathrm{GOD}$ \\
\hline Carbon (C 1s) & 89.6 & 86.9 \\
Oxygen (O 1s) & 10.0 & 8.2 \\
Nitrogen (N 1s) & - & 5.1 \\
\hline
\end{tabular}

${ }^{a}$ High Resolution.

resolution spectra. It was observed that the oxygen concentration is similar for all the samples and the nitrogen was detected only in the GOD, around $400 \mathrm{eV}$, proving that the functionalization of graphene oxide with dendrimer occurred successfully.

The carbon (C 1s) spectra for the GO and GOD, shown in Fig. 3(A) (II) and (B) (III), respectively, have as their main component at $(284.6 \mathrm{eV})$ the aromatic carbon $\left(\mathrm{C}-\mathrm{C} \mathrm{sp}^{2}\right)$ of the hexagonal planes of graphene [44-46].
The intensity of this component as much as the peak intensity of Plasmon $\pi \rightarrow \pi^{*}(\sim 291 \mathrm{eV})$ with the degree of aromatic of the system. Due to the presence of nitrogen in GOD (Fig. 3)(B), the fraction of the aromatic phase of carbon is lower ( $48 \%$ for GOD) compared to unmodified graphene oxide. The component at $285.3 \mathrm{eV}$ was attributed the $\mathrm{C}-\mathrm{CH}$ bonds of an aliphatic or $\mathrm{sp}^{3}$ structure, which includes a small contribution of hydrocarbons from surface contamination (ex situ measurements). For samples containing nitrogen (GOD - Fig. 3(B) (IV)), there is a component related to CN groups at $285.8 \mathrm{eV}$ [47-49], also seen as the main component of the nitrogen spectrum N 1s (400 eV) as illustrated in Fig. 3(B) (IV). In the higher binding energy tail others groups were be identified such as ether/alcohol ( $\mathrm{CO}$ in $286.3 \mathrm{eV})$, carbonyl $(\mathrm{C}=0)$ together with $\mathrm{NC}=\mathrm{O}$ groups of the functionalization in $287.6 \mathrm{eV}$ and Carboxylic groups $(\mathrm{HO}-\mathrm{C}=\mathrm{O})$ in $289.4 \mathrm{eV}$.

Fig. 3(B) (II) shows the modified graphene oxide (GOD), the appearance and increase of the intensity of the components related to nitrogen groups $\mathrm{CN}$ and $\mathrm{CN}=\mathrm{O}$, respectively, and also an increase 
of ether/Alcohol (CO) [49-51] when compared to unmodified graphene oxide $(A)$ (II).

Fig. 3(A) and (B) illustrate oxygen spectra for GO (III) and GOD (III), respectively. The spectra show four components corresponding to the $\mathrm{O}=\mathrm{C}$ groups at $531.5 \mathrm{eV}, \mathrm{O}-\mathrm{C}$ at $532.8 \mathrm{eV}, \mathrm{O}-\mathrm{C}=\mathrm{O}$ at $534.0 \mathrm{eV}$ and traces of water at $\sim 535 \mathrm{eV}$ [44-46]. For the GOD, an increase of the intensity of the component in $531.5 \mathrm{eV}$ is observed due to the presence of O-C-N groups.

As expected, for the nitrogen spectrum of the GO (Fig. 3(A) (IV)), it was not possible to find any component, due to the lack of nitrogen in the unmodified graphene oxide. As observed in Fig. 3(B) (IV) a moiety of amine groups of the dendrimer at $399.3 \mathrm{eV}$ was converted into $-\mathrm{N}-\mathrm{C}=\mathrm{O}$ groups due to functionalization of the carboxylic groups $(\mathrm{HO}-\mathrm{C}=\mathrm{O})$ of the graphene oxide. The central component at $400.1 \mathrm{eV}$ may be related to the $\mathrm{N}-\mathrm{C}$ and $\mathrm{HN}-\mathrm{C}$ of the dendrimer groups [47-49].

\subsection{Fourier transform infrared spectroscopy (FT-IR)}

The Fourier Transform Infrared Spectroscopy (FT-IR) spectra of GO and GO are shown in Fig. 4(A), indicating the successful dendrimer modification process. In the FT-IR spectra of GO (Fig. 4 A), a broad band at around 3713 to $3066 \mathrm{~cm}^{-1}$ was observed due to the presence of hydroxyl groups (Free) on the basal plane of GO. The peaks observed at 1630 and $1736 \mathrm{~cm}^{-1}$ were attributed to the presence of $\mathrm{C}=\mathrm{C}$ and $\mathrm{C}=\mathrm{O}$, respectively. Other bands were also observed at 1383 and $1115 \mathrm{~cm}^{-1}$ and are related to the asymmetric axial deformation of epoxide and alkoxides (CO) groups and the band at $972 \mathrm{~cm}^{-1}$ related to stretching $\mathrm{C}=\mathrm{C}$ of the graphene oxide structure [50].

For the functionalized graphene oxide with dendrimer (GOD), as shown in Fig. 4(B), a large absorption peak was observed in the region of 3728 to $3058 \mathrm{~cm}^{-1}$ characteristic of the axial deformation of the $\mathrm{OH}$ groups and to the stretching of the primary amine present in the dendrimer. The absorptions in the region of 1512 and $1461 \mathrm{~cm}^{-1}$ can be attributed to the stretches $\mathrm{CONH}$ and $\mathrm{CH}_{2}$, which are derived from the dendrimer [49].

The presence of primary amine groups in chain end of dendrimer allows the interaction of GOD with metal ions through the protonation of $\mathrm{NH}_{2}$ groups. In this context, aiming for future application we tested the reactivity of GOD with cupric ions $\left(\mathrm{Cu}^{2+}\right)$

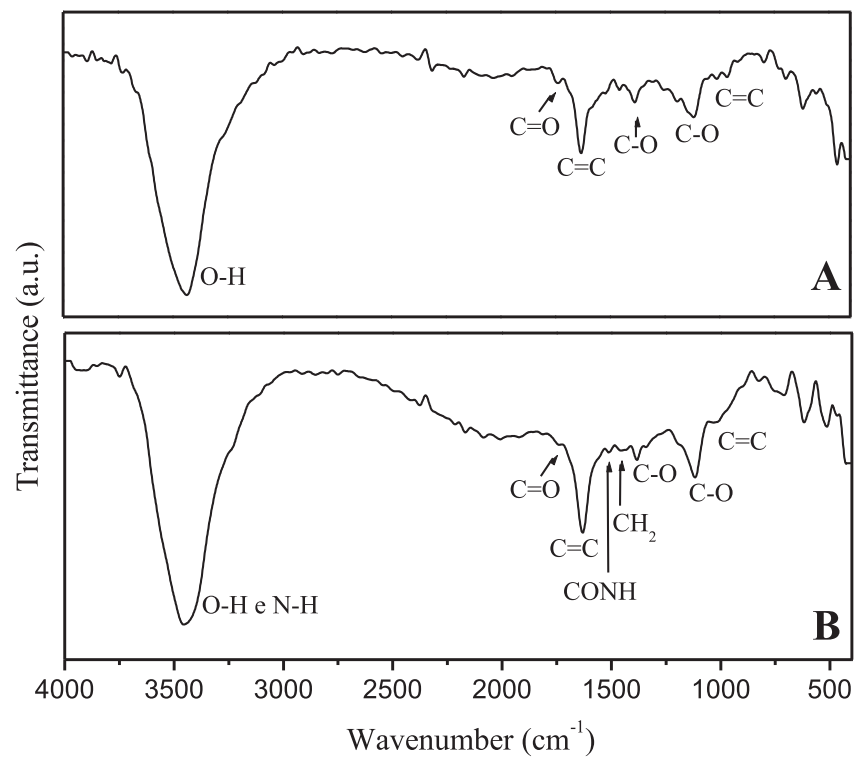

Fig. 4. Spectrum in the infrared region of: (A) GO and (B) GOD. in acid medium ( $\mathrm{pH}=3.0$, perchloric acid) and subsequent interaction with potassium hexacyanoferrate to generate a complex of mixed valence (intervalence complex). Fig. 5(A) and (B) illustrate infrared spectra for the potassium hexacyanoferrate (III) and for the intervalence complex formed GODHCu, respectively. A band in the region between 3680 and $3150 \mathrm{~cm}^{-1}$ attributed to the axial deformation of the $\mathrm{OH}$ groups was observed in the potassium hexacyanoferrate spectrum shown in Fig. 5(A), and a narrow and medium band at $1620 \mathrm{~cm}^{-1}$ attributed to the $\mathrm{H}-\mathrm{O}-\mathrm{H}$ bond of water. An important vibrations around $2035 \mathrm{~cm}^{-1}$, referring to the stretching of the $\mathrm{C} \equiv \mathrm{N}[50]$. For the spectrum shown in Fig. 5(B), characteristic absorption bands of precursor materials (GO and GOD) were observed, as well as a significant vibration occurring near $2100 \mathrm{~cm}^{-1}$, referring to $\mathrm{C} \equiv \mathrm{N}$ vibrations [51].

The stretch displacement $\left(\sim 33 \mathrm{~cm}^{-1}\right)$ for the higher frequency region of the $\mathrm{C} \equiv \mathrm{N}$ of $\mathrm{GODHCu}$ relative to the precursor $\mathrm{HCF}$, confirms the formation of the intervalence complex where $\mathrm{Cu}^{2+}$ is bound to the metal center via $\mathrm{CN}$ bridge $\left(\mathrm{Fe}^{3+}-(\mathrm{CN})-\mathrm{Cu}^{2+}\right)[52]$.

\subsection{X-ray diffraction $(X R D)$}

Fig. 6 represents the XRD pattern of GO (A) and GOD (B). For the graphene oxide $(A)$, the peaks were exactly observed at $2 \theta=26.27^{\circ}$ and $43.46^{\circ}$, already for the modified graphene oxide (GOD) (B), the peaks occurred at $2 \theta=26.51^{\circ}$ and $43.75^{\circ}$. The peaks around at $2 \theta=26^{\circ}$ where attributed to the diffraction of the (002) plane.

After the modification of the graphene with the dendrimer, the number of layers was estimated. For the calculation of the average number of graphene layers $(n)$ in the modified graphene oxide graphite, was applied of Debye-Scherrer equations (1) and (2) $[53,54]$.

$L a=(k \lambda) /\left(\beta_{h k l} \cos \theta\right)$

$n=L a / d_{h k l}$

where $L a$ (stacking height), $\beta$ (full width half maxima-FWHM), $n$ (number of graphene layers), $\mathrm{d}_{002}$ (interlayer spacing) were obtained by using the data from XRD patterns.

The increase of layer numbers from about 30 to 40 after functionalization was the result of the sonication process, stepwise chemical procedure used in this present report. This fact was

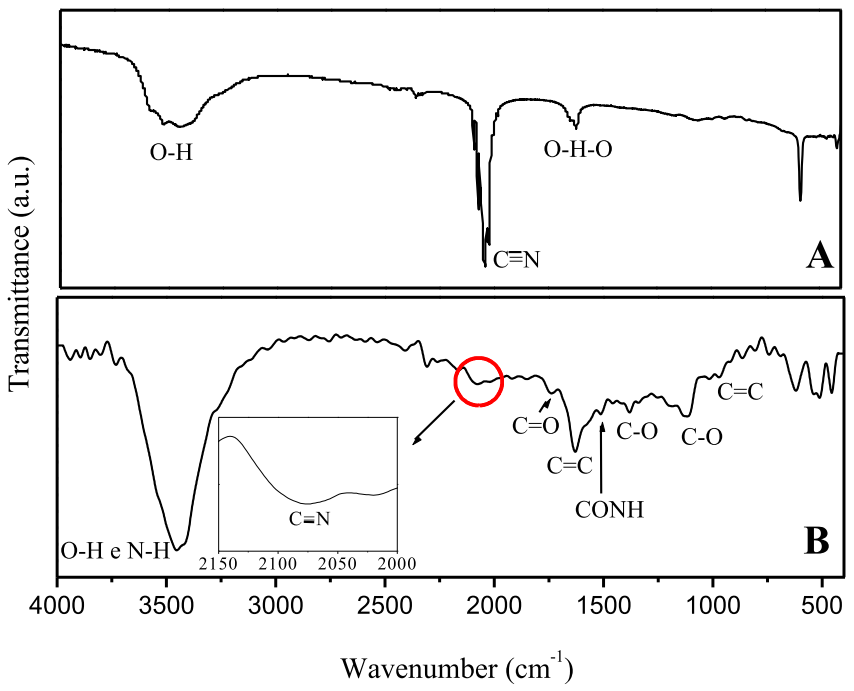

Fig. 5. Spectrum in the infrared region of: (A) HCF e (B) GODHCu. 


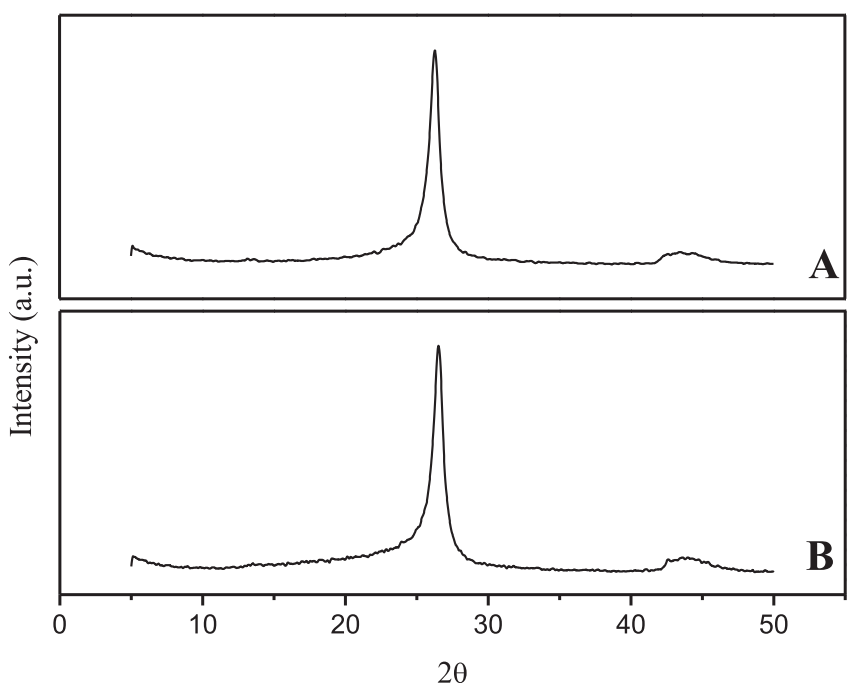

Fig. 6. XRD patterns of GO (A) and GOD (B).

attributed to a high effect dispersion of previous GO. The application of this functionalization method can increase the number of graphene layers and consequently, the interplanar spacing increases when the dendrimer linkage on the graphene oxide surface. Table 3 list the XRD powder data obtained for two materials.

\subsection{Scanning Electron Microscopy (SEM)}

The SEM image of the GO and GOD shown in Fig. 7(A) and (B) respectively. GO reveals aggregate and individual flakes randomly with sheet-type morphology. After functionalization the morphology of the synthesized GOD resembles a flake sheet structure aggregate with the largest dimension as a consequence of synthetic method employed. Similar textures obtained by GO and GOD have been reported by other authors $[43,55]$.

\subsection{Thermogravimetric analysis (TGA)}

TGA is a reliable tool to investigating the thermal stability of various structural carbon forms. As observed in Fig. 8, both thermograms were quite similar. In the thermogram presented by the GO (Fig. 8(A)) it was verified that GO thermally decomposed in the following three stages of mass loss. The first stage (4\%) up to $100{ }^{\circ} \mathrm{C}$ was associated with the thermal desorption of water molecules physically adsorbed onto the hydrophilic GO surface. The second stage $100-450{ }^{\circ} \mathrm{C}(14 \%)$ and third stage $450-650{ }^{\circ} \mathrm{C}(94 \%)$ are related to the decomposition of more stable oxygen-containing functional groups to $\mathrm{CO}$ and $\mathrm{CO}_{2}[34,56,57]$.

Fig. 8(B) shows the thermogram of the graphene oxide modified with dendrimer (GOD), where three stages of mass loss were observed. The first $30-100{ }^{\circ} \mathrm{C}(4 \%)$, being attributed to water physically adsorbed by the material. The second stage occurred from $100-230{ }^{\circ} \mathrm{C}(7 \%)$ and third $230-400$ (9.2), which was attributed oxygen-containing and decomposition of functional groups and dendrimer chain, respectively. The third due the

Table 3

XRD powder data obtained for GO and GOD patterns materials.

\begin{tabular}{lllll}
\hline Sample & $2 \theta\left({ }^{\circ}\right)$ & $\mathrm{d}_{002}(\mathrm{~nm})$ & La $(\mathrm{nm})$ & $\mathrm{n}$ \\
\hline GO & 26.27 & 0.3353 & 9.98 & 29.8 \\
GOD & 26.51 & 0.3356 & 13.30 & 39.6 \\
\hline
\end{tabular}

complete oxidative decomposition (77.8\%) of the graphitic substrate over $400-650{ }^{\circ} \mathrm{C}$. The final residue was $2 \%$ that is caused by the pyrolysis of the carbon skeleton of GO [58].

\subsection{Electroanalytical application of GODHCu}

GOD has a large amount of $\mathrm{NH}_{2}$ chain end groups that can act as active sites. In this way GOD was used as a matrix in the copper complexation with potassium hexacyanoferrate following two steps: GOD is protonated $(\mathrm{pH} 3.0)$ and electrostatically interact with potassium hexacyanoferrate $(\mathrm{GODH})$, followed by a reaction with copper ions (GODHCu). At pH 3.0, more primary and tertiary amine groups are protonated to provide more active sites binding negative charged hexacyanoferrate (III) ions.

Differential pulse voltammetry (DPV) compared to cyclic voltammetry provides a current of highly sensitivity and better detection and, therefore, have been chosen for the detection of $\mathrm{L}_{-}$ dopamine. Therefore, as an application, GODHCu was tested for the detection of L-dopamine using a differential pulse voltammetry (DPV).

The DPV of the modified electrode containing GODHCu exhibited three anodic peaks (Fig. 9(C)) with potential 0.11 (I), 0.28 (II) and $0.78 \mathrm{~V}$ (III) $v s \mathrm{Ag} / \mathrm{AgCl}_{\text {(sat.) }}\left(\mathrm{KCl} 1.0 \mathrm{~mol} \mathrm{~L}^{-1} ; v=10 \mathrm{mV} \mathrm{s}^{-1}\right.$; amplitude $50 \mathrm{mV}$ ) attributed to $\mathrm{Cu}^{0} / \mathrm{Cu}^{\mathrm{I}}, \mathrm{Cu}^{\mathrm{I}} / \mathrm{Cu}^{\mathrm{II}}$ e $\mathrm{Fe}^{\mathrm{II}}(\mathrm{CN})_{6} /$ $\mathrm{Fe}^{\mathrm{III}}(\mathrm{CN})_{6}$ redox process respectively. For comparison, unmodified graphite paste electrode in the absence of L-dopamine $(A)$ didn't show any redox process in the potential range between -0.2 and $1.1 \mathrm{~V}$, however, in the presence of $5.0 \times 10^{-3} \mathrm{~mol} \mathrm{~L}^{-1}$ L-dopamine (B), it was possible to observe a single redox process of with $\mathrm{E}^{\theta^{\prime}}=0.39 \mathrm{~V}$. An enhancement in the oxidation peak current in the anodic process was observed with addition of $5.0 \times 10^{-3} \mathrm{~mol} \mathrm{~L}^{-1} \mathrm{~L}^{-}$ dopamine (I) (D). Simultaneously with L-dopamine additions the anodic current intensity of the process (III) decrease (D) and the peak II moves to cathodic region.

Fig. 10 illustrates the analytical curve used to detect L-dopamine. The analytical curve presented a linear response in the concentration range from $1.0 \times 10^{-7}$ to $1.0 \times 10^{-5} \mathrm{~mol} \mathrm{~L}^{-1}$ with a corresponding equation $\mathrm{Y}(\mathrm{A})=1.706 \times 10^{-5}+0.862$ [L-dopamine] and a correlation coefficient $\mathrm{r}^{2}=0.998$. The detection limit (3SD/slope) was $6.36 \times 10^{-7} \mathrm{~mol} \mathrm{~L}^{-1}$ with a relative standard deviation of $\pm 4 \%$ $(n=3)$ and an amperometric sensitivity of $0.872 \mathrm{~A} / \mathrm{mol} \mathrm{L}^{-1}$.

A reasoned explanation for a linear decrease of peak III is still being investigated, but the of decreased peak III was tentatively attributed to a possible chemical formation of a complex from dopaminequinone that deposits on the electrode surface, the lead to a decrease of electroactivity of intervalence complex (Fe (III) metal center), inhibiting the oxidation process of peak III. This was easily confirmed, because when washing the electrode with distilled water the oxidation of peak III returns as before. In this way contrary to the works found in the literature to detection of $\mathrm{L}^{-}$ dopamine using $\mathrm{M}\left[\mathrm{Fe}(\mathrm{CN})_{6}\right]$ where $\mathrm{M}=\mathrm{Ag}, \mathrm{Cu}, \mathrm{Zn}, \mathrm{Ni}$, Th, $\mathrm{La}, \mathrm{Cu}$ [59-64] the electro-oxidation does not occur in the metal center of $\mathrm{Fe}^{\mathrm{III}}$, but with copper that is in the outer coordination sphere of intervalence complex.

The electrocatalytic oxidation of L-dopamine occurs as follows: $\mathrm{Cu}^{+}$produced during anodic scan, oxidize the L-dopamine to Dopaminequinone [65-67] when it is chemically reduced to $\mathrm{Cu}^{0}$, which will again be electrochemically oxidized to $\mathrm{Cu}^{+}$. This way the electro oxidation occurs in peak I according to equations (3) and (4).

$2 \mathrm{Cu}^{0} \rightleftarrows 2 \mathrm{Cu}^{+}+2 \mathrm{e}^{-}$

$\mathrm{D}+2 \mathrm{Cu}^{+} \rightleftarrows \mathrm{Dq}+2 \mathrm{H}^{+}+2 \mathrm{Cu}^{0}$ 

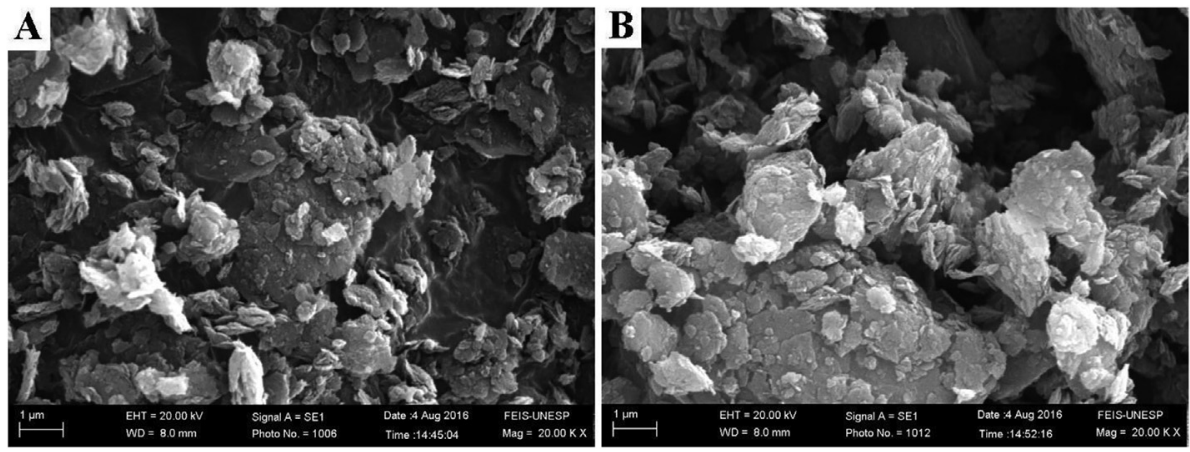

Fig. 7. SEM images of: GO (A) and GOD (B).

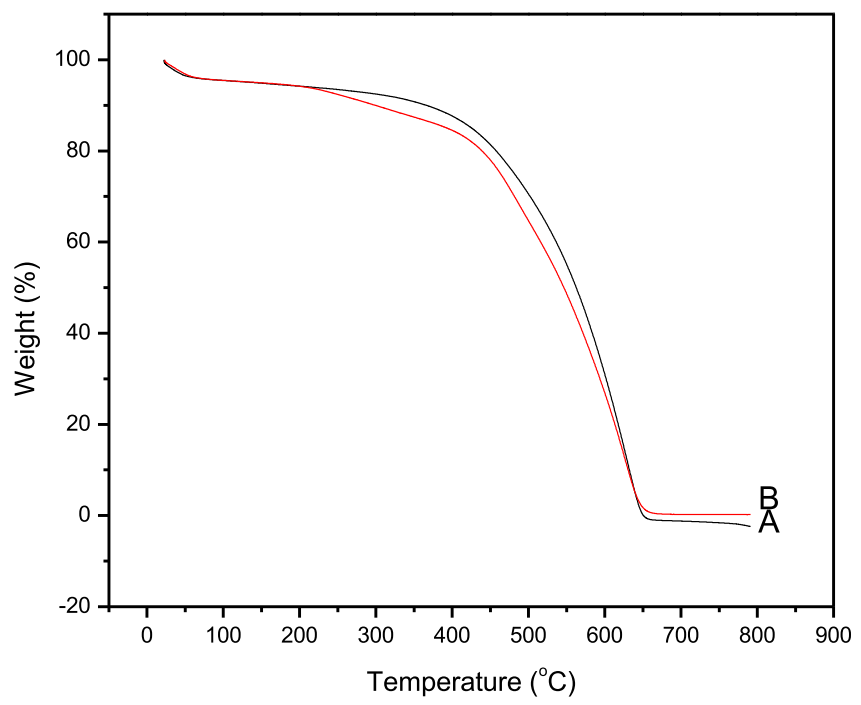

Fig. 8. Thermogram of: GO (A) and GOD (B).

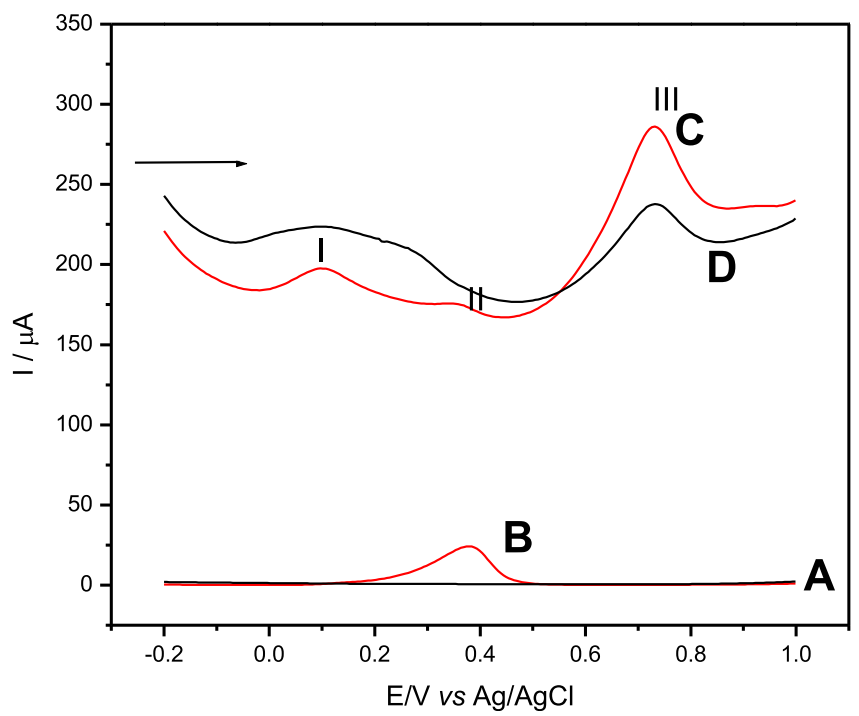

Fig. 9. Differential pulse voltammograms of: (A) unmodified graphite paste electrode in the absence of L-dopamine, (B) unmodified graphite paste electrode in presence of $5.0 \times 10^{-3} \mathrm{~mol} \mathrm{~L}^{-1}$ L-dopamine, (C) graphite paste electrode modified with GODHCu in the absence of L-dopamine, (D) graphite paste modified with GODHCu in presence of $5.0 \times 10^{-3} \mathrm{~mol} \mathrm{~L}^{-1}$ L-dopamine.

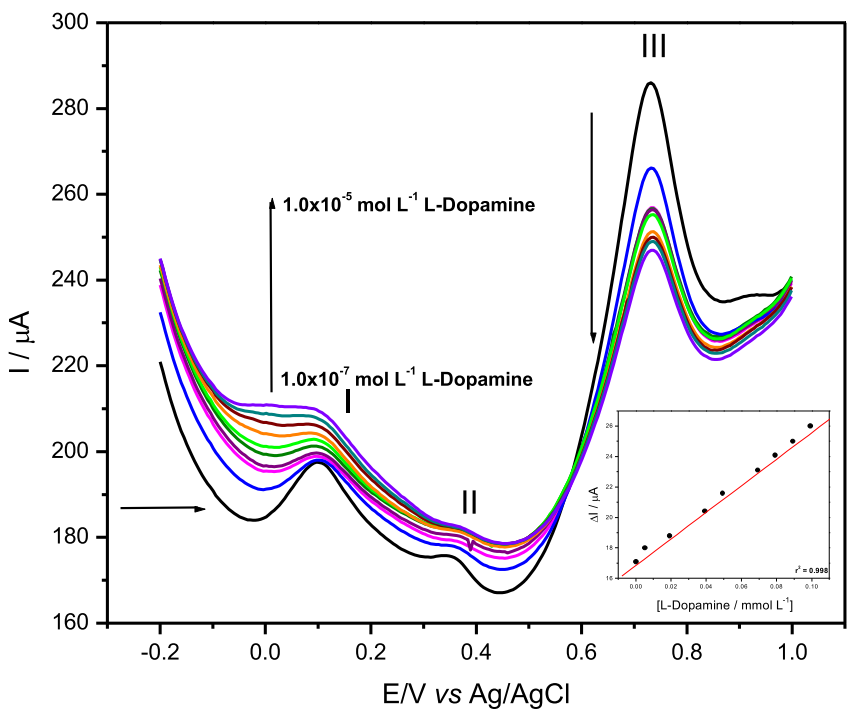

Fig. 10. Differential pulse voltammograms obtained for the modified graphite paste electrode with GODHCu in the presence of different L-dopamine concentrations $\left(1.0 \times 10^{-7}\right.$ to $\left.1.0 \times 10^{-5} \mathrm{~mol} \mathrm{~L}^{-1}\right)\left(\mathrm{E}_{\mathrm{ap}}=0.11 \mathrm{~V} ; \mathrm{KCl} 1.0 \mathrm{~mol} \mathrm{~L}^{-1}, \mathrm{pH} 7.0 ; v=10 \mathrm{mV} \mathrm{s}^{-1}\right.$; amplitude $(\mathrm{W})=50 \mathrm{mV} ; 20 \%(\mathrm{w} / \mathrm{w})$ ) (inserted: analytical curve).

where $\mathrm{D}=\mathrm{L}$-dopamine and $\mathrm{Dq}=$ dopaminequinone.

GODHCu exhibits excellent electrocatalytic activity for the oxidation of L-dopamine, with a reduction in over potential about $291 \mathrm{mV}$ than the unmodified electrode. The performance of the fabricated electrode when compared with any reported sensors, are comparative [68-70] or better [71-73] than those of the other sensors reported in the literature.

Table 4 presents a comparison of similar reports in the literature for L-dopamine detection. These results show the analytical benefits obtained by use of GODHCu, which showed some good electroanalytical parameters when compared with previous reports.

\section{Conclusions}

The chemical modification of graphene oxide with DAB-Am-16 were successfully performed as confirmed by various spectroscopic measurements such as Raman, XPS, FT-IR, DRX. By XPS and FT-IR we conclude that dendrimer was covalently bonding onto graphene oxide via the amide formation between any peripheral amine groups dendrimer and carboxyl groups in graphene oxide. The thermal stability is maintained after chemical modification of graphene oxide. As an application, after reaction of the hybrid material with copper and hexacyanoferrate ions (GODHCu) was 
Table 4

Comparison of this work previous reports of L-dopamine detection.

\begin{tabular}{|c|c|c|c|}
\hline Electrode Material & $\begin{array}{l}\text { Linear Range } \\
\left(\mathrm{mol} \mathrm{L}^{-1}\right)\end{array}$ & Limit Detection $\left(\mathrm{mol} \mathrm{L}^{-1}\right)$ & Reference \\
\hline $\mathrm{PbO}_{2}$ immobilized in Polyester/GPE & $2.6 \times 10^{-4}$ to $1.2 \times 10^{-3}$ & $2.50 \times 10^{-5}$ & [74] \\
\hline GRP-SIALNB-MB/GPE & $5.0 \times 10^{-6}$ to $5.0 \times 10^{-4}$ & $1.49 \times 10^{-6}$ & [75] \\
\hline CuHSA/GPE & $5.0 \times 10^{-5}$ to $1.0 \times 10^{-4}$ & $1.70 \times 10^{-4}$ & [59] \\
\hline CuHSA/GPE & $1.0 \times 10^{-4}$ to $8.0 \times 10^{-4}$ & $5.27 \times 10^{-5}$ & [59] \\
\hline $\mathrm{GODHCu} / \mathrm{GPE}^{\mathrm{a}}$ & $1.0 \times 10^{-7}$ to $1.0 \times 10^{-5}$ & $6.36 \times 10^{-7}$ & This work \\
\hline
\end{tabular}

a Graphite paste electrode.

successfully tested in the electrocatalytic detection of L-dopamine using a graphite paste electrode. The analytical curve showed a linear response in the concentration range from $1.0 \times 10^{-7}$ to $1.0 \times 10^{-5}$ mol $\mathrm{L}^{-1}$ with a corresponding equation $\mathrm{Y}$ $(\mathrm{A})=1.706 \times 10^{-5}+0.862$ [L-dopamine] and a correlation coefficient $\mathrm{r}^{2}=0.998$. The detection limit was $6.36 \times 10^{-7} \mathrm{~mol} \mathrm{~L}^{-1}$ with a relative standard deviation of $\pm 4 \%(n=3)$ and an amperometric sensitivity of $0.862 \mathrm{~A} / \mathrm{mol} \mathrm{L}^{-1}$. This material (GOD) is a potential candidate for the development of sensitive electrochemical sensors and other catalytic applications that will be tested in the future.

\section{Acknowledgment}

The authors would like to express their gratitude for the financial support by the Fundação de Amparo à Pesquisa do Estado de São Paulo (FAPESP- Proc. 2015/20397) and LEFE laboratory for XPS analysis.

\section{References}

[1] J. Kim, L.J. Cote, F. Kim, W. Yuan, K.R. Shull, J. Huang, Graphene oxide sheets at interfaces, J. Am. Chem. Soc. 132 (2010) 8180-8186.

[2] B.C. Brodie, On the atomic weight of graphite, Phil. Trans. R. Soc. Lond. 149 (1859) 249-259.

[3] V. Georgakilas, M. Otyepka, A.B. Bourlinos, V. Chandra, N. Kim, K.C. Kemp, P. Hobza, R. Zboril, K.S. Kim, Functionalization of graphene: covalent and noncovalent approaches, derivatives and applications, Chem. Rev. 112 (2012) 6156-6214.

[4] K.S. Novoselov, V.I. Fal'ko, L. Colombo, P.R. Gellert, M.G. Schwab, K. Kim, A roadmap for grapheme, Nature 490 (2012) 192-200.

[5] C. Chung, Y.K. Kim, D. Shin, S.R. Ryoo, B.H. Hong, D.H. Min, Biomedical applications of graphene and graphene oxide, Acc. Chem. Res. 46 (2013) 2211-2224.

[6] H.Y. Mao, S. Laurent, W. Chen, O. Akhavan, M. Imani, A.A. Ashkarran, M. Mahmoudi, Graphene: promises, facts, opportunities, and challenges in nanomedicine, Chem. Rev. 113 (2013) 3407-3424.

[7] S. Eigler, Y. Hu, Y. Ishii, A. Hirsch, Controlled functionalization of graphene oxide with sodium azide, Nanoscale 5 (2013) 12136-12139.

[8] J. Kim, L.J. Cote, J.X. Huang, Two dimensional soft material: new faces of graphene oxide, Acc. Chem. Res. 45 (2012) 1356-1364.

[9] A.T. Wright, E.V. Anslyn, Inside front cover, Chem. Soc. Rev. 35 (2006) 14-28.

[10] Z. Liu, J.T. Robinson, X. Sun, H. Dai, PEGylated nanographene oxide for delivery of water-insoluble cancer drugs, J. Am. Chem. Soc. 130 (2008) 10876-10877.

[11] D. Chen, H. Feng, J. Li, Graphene oxide: preparation, functionalization, and electrochemical applications, Chem. Rev. 112 (2012) 6027-6053.

[12] T. Kuila, S. Bose, P. Khanra, A.K. Mishra, N.H. Kim, J.H. Lee, Recent advances in graphene-based biosensors, Biosens. Bioelectron. 26 (2011) 4637-4648.

[13] L. Zhao, R. He, K.T. Rim, T. Schiros, K.S. Kim, H. Zhou, C. Gutierrez, S.P. Chockalingam, C.J. Arguello, L. Palova, D. Nordlund, M.S. Hybertsen, D.R. Reichman, T.F. Heinz, P. Kim, A. Pinczuk, G.W. Flynn, A.N. Pasupathy, Visualizing individual nitrogen dopants in monolayer graphene, Science 333 (2011) 999-1003.

[14] A.M. Dimiev, L.B. Alemany, J.M. Tour, Graphene oxide. Origin of Acidity, its instability in water, and a new dynamic structural model, ACS Nano 7 (2013) $576-588$.

[15] C. Hou, Q. Zhang, Y. Li, H. Wang, Graphene-polymer hydrogels with stimulussensitive volume changes, Carbon 50 (2012) 1959-1965.

[16] A. Paul, A. Hasan, H.A. Kindi, A.K. Gaharwar, V.T. Rao, M. Nikkhah, S.R. Shin, D. Krafft, M.R. Dokmeci, D. Shum-Tim, A. Khademhosseini, Injectable graphene oxide/hydrogel-based angiogenic gene delivery system for vasculogenesis and cardiac repair, ACS Nano 8 (2014) 8050-8062.

[17] H. Bai, C. Li, X.L. Wang, G.Q. Shi, A pH-sensitive graphene oxide composite hydrogel, Chem. Commun. 46 (2010) 2376-2378.

[18] Y.X. Xu, Q.O. Wu, Y.Q. Sun, H. Bai, G.Q. Shi, Three dimensional self-assembly of graphene oxide and DNA into multifunctional hydrogels, ACS Nano 4 (2010) 7358-7362.

[19] S. Goenka, V. Sant, S. Sant, Graphene-based nanomaterials for drug delivery and tissue engineering, J. Control. Release 173 (2014) 75-88.

[20] D.R. Dreyer, S. Park, C.W. Bielawski, R.S. Ruoff, The chemistry of graphene oxide, Chem. Soc. Rev. 39 (2010) 228-240.

[21] Y. Xue, H. Chen, D. Yu, S. Wang, M. Yardeni, Q. Dai, M. Guo, Y. Liu, F. Lu, J. Qu, L. Dai, Oxidizing metal ions with graphene oxide: the in situ formation of magnetic nanoparticle on self-reduced graphene sheets for multifunctional applications, Chem. Commun. 47 (2011) 11689-11691.

[22] K.P. Loh, Q. Bao, P.K. Ang, J. Yang, The chemistry of graphene, J. Mater. Chem. 20 (2010) 2277-2289.

[23] S.Y. Yang, C.C.M. Ma, C.C. Teng, Y.W. Huang, S.H. Liao, Y.L. Huang, H.W. Tien, T.M. Lee, K.C. Chiou, Effect of functionalized carbon nanotubes on the thermal conductivity of epoxy composites, Carbon 48 (2010) 592-603.

[24] D.A. Tomalia, Birth of a new macromolecular architecture: dendrimers as quantized building blocks for nanoscale synthetic polymer chemistry, Prog. Polym. Sci. 30 (2005) 294-324.

[25] S.K. Choi, T. P. Thomas, M.H. Li, A Desai, A Kotlyar, J.R. Baker, Photochemica release of methotrexate from folate receptor targeting PAMAM dendrimer nanoconjugate, Photochem. Photobiol. Sci. 11 (2012) 653-660.

[26] G.R. Newkome, Z. Yao, G.R. Baker, V.K. Gupta, Cascade molecules: a new approach to micelles. A [27]-arborol, J. Org. Chem. 50 (1985) 2003-2004.

[27] A.M. Caminade, R. Laurent, J.P. Majoral, Characterization of dendrimers, Adv. Drug Deliv. Rev. 57 (2005) 2130-2146.

[28] P.E. Froehling, Dendrimers and dyes - a review, Dyes Pigments 48 (2001) $187-195$.

[29] D.A. Tomalia, A.M. Naylor, W.A. Goddard, Starburst dendrimers: molecularlevel control of size, shape, surface chemistry, topology, and flexibility from atoms to macroscopic matter, Angew. Chem. Int. Ed. (English) 29 (1990) $138-175$.

[30] I.M. El- Deeb, S.H. Lee, A new eficiente convergent synthesis of conjugated aryl- containing dendrimers, Bull. Korean Chem. Soc. 31 (2010) 1994-2001.

[31] T.T. Felippotti, D.R. Do Carmo, L.L. Paim, N.R. Stradiotto, U.O. Bicalho, C.A. Parada, R. Grillo, L.F. Fraceto, N.C. Coimbra, Effect of a nanostructured dendrimer-naloxonzine complex on endogenous opioid peptides 1-receptormediated post-ictal antinociception, Nanomedicine 7 (2011) 871-880.

[32] U. Boas, J.B. Christensen, P.M.H. Heegaard, Dendrimers: design, synthesis and chemical properties, J. Mater. Chem. 16 (2006) 3785-3798.

[33] J.-A. Jee, L.A. Spagnuolo, J.G. Rudick, Convergent synthesis of dendrimers via the Passerini three-component reaction, Org. Lett. 14 (2012) 3292-3295.

[34] Y. Yuan, G. Zhang, Y. Li, G. Zhang, F. Zhang, X. Fan, Poly(amidoamine) modified graphene oxide as an efficient adsorbent for heavy metal ions, Polym. Chem. 4 (2013) 2164-2167.

[35] F. Zhang, B. Wang, S. He, R. Man, Preparation of graphene oxide/polyamidoamine dendrimers and their adsorption properties toward some heavy metal ions, J. Chem. Eng. Data 59 (2014) 1719-1726.

[36] D.R. do Carmo, S. Gabriel Jr., U.O. Bicalho, C.A. Picon, L.L. Paim, Copper hexacyanoferrate formation on the modified silica surface with DAB-Am-16 dendrimer, Macromol. Symp. 299 (1) (2011) 206-214.

[37] Y. Xue, Y. Liu, F. Lu, J. Qu, H. Chen, L. Dai, Functionalization of graphene oxide with polyhedral oligomeric silsesquioxane (POSS) for multifunctional applications, J. Phys. Chem. Lett. 3 (2012) 1607-1612.

[38] L.R. Cumba, U.O. Bicalho, D.R. do Carmo, Voltammetric studies of cobalt hexacyanoferrate formed on the titanium (IV) phosphate surface and its application to the determination of sulfite, Int. J. Electrochem. Sci. 7 (2012) 2123-2135.

[39] K.N. Kudin, B. Ozbas, H.C. Schniepp, R.K. Prud'homme, I.A. Aksay, R. Car Raman spectra of graphite oxide and functionalized graphene sheets, Nano Lett. 8 (2008) 36-41.

[40] Y. Piao, T. Wu, B. Chen, One-step synthesis of graphene oxidepolyamidoamine dendrimer nanocomposite hydrogels by self-assembly, Ind Eng. Chem. Res. 55 (2016) 6113-6121.

[41] S. Eigler, C. Dotzer, A. Hirsch, Visualization of defect densities in reduced graphene oxide, Carbon 50 (2012) 3666-3673.

[42] F. Tuinstra, J.L. Koenig, Raman spectrum of graphite, J. Chem. Phys. 53 (1970) 1126-1130.

[43] T. Somanathan, K. Prasad, K. Ostrikov, A. Saravanan, V.M. Krishna, Graphene oxide synthesis from agro waste, Nanomaterials 5 (2015) 826-834.

[44] C. Tao, J. Wang, S. Qin, Y. Lv, Y. Long, H. Zhua, Z. Jiang, Fabrication of pH- 
sensitive graphene oxide-drug supramolecular hydrogels as controlled release system, J. Mater. Chem. 22 (2012) 24856-24861.

[45] B. Yu, X. Wang, X. Qian, W. Xing, H. Yang, L. Ma, Y. Lin, S. Jiang, L. Song, Y. Hu, S. Lo, Functionalized graphene oxide/phosphoramide oligomer hybrids flame retardant prepared via in situ polymerization for improving the fire safety of polypropylene, RSC Adv. 4 (2014) 31782-31794.

[46] S. Drewniak, R. Muzyka, A. Stolarczyk, T. Pustelny, M. Kotyczka-Moranska, M. Setkiewicz, Studies of reduced graphene oxide and graphite oxide in the aspect of their possible application in gas sensors, Sensors 16 (2016) 1-16.

[47] R.K. Layek, A.K. Nandi, A review on synthesis and properties of polymer functionalized graphene, Polymer 54 (2013) 5087-5103.

[48] Q. Zhao, C. Bai, W. Zhang, Y. Li, G. Zhang, F. Zhang, X. Fan, Catalytic epoxidation of olefins with graphene oxide supported copper (Salen) complex, Ind. Eng. Chem. Res. 53 (2014) 4232-4238.

[49] Y. Yuan, G. Zhang, Y. Li, G. Zhang, F. Zhang, X. Fan, Poly(amidoamine) modified graphene oxide as an efficient adsorbent for heavy metal ions, Polym. Chem. 4 (2013) 2164-2167.

[50] E.Y. Choi, T.H. Han, J. Hong, J.E. Kim, S.H. Lee, H.W. Kim, S.O. Kim, Noncovalent functionalization of graphene with end-functional polymers, J. Mater. Chem. 20 (2010) 1907-1912.

[51] R.M. Silverstein, F.X. Welbster, Spectrometric Identification of Organic Compounds, John Wiley and Sons, New York, 1996.

[52] K. Nakamoto, Infrared and Raman Spectra of Inorganic and Coordination Compounds, John Wiley and Sons, New York, 1986.

[53] A.L. Patterson, The Scherrer formula for X-ray particle size determination 56 (1939) 978-982.

[54] B. Saner, F. Okyay, Y. Yürüm, Utilization of multiple graphene layers in fuel cells. 1. An improved technique for the exfoliation of graphene-based nanosheets from graphite, Fuel 89 (2010) 1903-1910.

[55] S. Bykkam, K.V. Rao, S. Chakra, T. Thunugunta, Synthesis and Characterization of graphene oxide and its antimicrobial activity against Klebseilla and Staphylococcus, Int. J. Adv. Biotechnol. Res. 4 (2013) 142-146.

[56] T. Soltani, B.-K. Lee, A benign ultrasonic route to reduced graphene oxide from pristine graphite, J. Colloid Interface Sci. 486 (2017) 337-343.

[57] Y. Zhang, H.-L. Ma, Q. Zhang, J. Peng, J. Li, M. Zhai, Z.-Z. Yu, Facile synthesis of well-dispersed graphene by $\gamma$-ray induced reduction of graphene oxide, J. Mater. Sci. 22 (2012) 13064-13069.

[58] W.-Q. Chen, Q.-T. Li, P.-H. Li, Q.-Y. Zhang, Z.-S. Xu, P.K. Chu, X.-B. Wang, C.F. Yi, In situ random co-polycondensation for preparation of reduced graphene oxide/polyimide nanocomposites with amino-modified and chemically reduced graphene oxide, J. Mater. Sci. 50 (2015) 3860-3874.

[59] D.R. Silvestrini, T.F.S. Da Silveira, U.O. Bicalho, D.R. Do Carmo, Voltammetric Behavior of a chemically modified Silsesquioxane with 4-amino-5-phenyl-4h$[1,2,4]$-triazole-3-thiol and its application for detection of L-dopamine, Int. J. Electrochem. Sci. 10 (2015) 2839-2858.

[60] M. Noroozifar, M. Khorasani-Motlagh, A. Taheri, Preparation of silver hexacyanoferrate nanoparticles and its application for the simultaneous determination of ascorbic acid, dopamine and uric acid, Talanta 80 (2010) $1657-1664$

[61] J.C. Kemmegne-Mbouguen, L. Agnes, E. Mouafo-Tchinda, E. Ngameni,
Electrochemical determination of uric acid, dopamine and tryptophan at zinc hexacyanoferrate clay modified electrode, Electroanalysis 27 (2015) 2387-2398.

[62] P. Prabhu, R.S. Babu, S.S. Narayanan, Amperometric determination of 1-dopa by nickel hexacyanoferrate film modified gold nanoparticle graphite composite electrode, Sens. Actuators B Chem. 156 (2011) 606-614.

[63] K. Farhadi, F. Kheiri, M. Golzan, Th(IV)-hexacyanoferrate modified carbon paste electrode as a new electrocatalytic probe for simultaneous determination of ascorbic acid and dopamine from acidic media, J. Braz. Chem. Soc. 19 (2008) 1405-1412.

[64] T. Selvaraju, R. Ramaraj, Signal amplification of dopamine using lanthanum hexacyanoferrate-modified electrode, J. Chem. Sci. 126 (2014) 11-16.

[65] P. Muñoz, S. Huenchuguala, I. Paris, J. Segura-Aguilar, Dopamine oxidation and autophagy, Park. Dis. 2012 (2012) 1-13.

[66] S. Jana, M. Sinha, D. Chanda, T. Roy, K. Banerjee, S. Munshi, B.S. Patro, S. Chakrabarti, Mitochondrial dysfunction mediated by quinone oxidation products of dopamine: implications in dopamine cytotoxicity and pathogenesis of Parkinson's disease, Biochim. Biophys. Acta, Mol. Basis Dis. 1812 (2011) 663-673.

[67] C.M.F. Calixto, S.X. Dos Santos, E.T.G. Cavalheiro, Eletrodo compósito à base de grafite-Araldite $^{\mathbb{R}}$ : aplicações didáticas - parte II, Quim. Nova 37 (2014) $367-372$.

[68] Y. Huang, C. Cheng, X. Tian, B. Zheng, Y. Li, H. Yuan, D. Xiao, M.M.F. Choi, Lowpotential amperometric detection of dopamine based on $\mathrm{MnO}_{2}$ nanowires/ chitosan modified gold electrode, Electrochem. Acta 89 (2013) 832-839.

[69] Y. Fan, H.-T. Lu, J.-H. Liu, C.-P. Yang, Q.-S. Jing, Y.-X. Zhang, X.-K. Yang, K.J. Huang, Hydrothermal preparation and electrochemical sensing properties of $\mathrm{TiO}_{2}$ - graphene nanocomposite, Colloids Surf. B 83 (2011) 78-82.

[70] Z. Zheng, H. Qiu, M. Zheng, S. Weng, Z. Huang, R. Xian, X. Lin, Selective electrochemical determination of dopamine in serum in the presence of ascorbic acid and uric acid by using a CuO nanoleaf electrode, Anal. Methods 6 (2014) 7923-7927.

[71] D. Han, T. Han, C. Shan, A. Ivaska, L. Niu, Simultaneous determination of ascorbic acid, dopamine and uric acid with chitosan-graphene modified electrode, Electroanalysis 22 (2010) 2001-2008.

[72] S.S.L. Castro, R.J. Mortimer, M.F. De Oliveira, N.R. Stradiotto, Electrooxidation and determination of dopamine using a nafion ${ }^{\mathbb{R}}$-cobalt hexacyanoferrate film modified electrode, Sensors 8 (2008) 1950-1959.

[73] K. Khun, Z.H. Ibupoto, X. Liu, N.A. Mansor, A.P. Turner, V. Beni, M. Willander, An electrochemical dopamine sensor based on the $\mathrm{ZnO} / \mathrm{CuO}$ nanohybrid structures, J. Nanosci. Nanotechnol. 14 (2014) 6646-6652.

[74] H.C. de Melo, A.P.D. Seleghim, W.L. Polito, O. Fatibello-Filho, I.C. Vieira, Simultaneous differential pulse voltammetric determination of L-dopa and carbidopa in pharmaceuticals using a carbon paste electrode modified with lead dioxide immobilized in a polyester resin, J. Braz. Chem. Soc. 18 (2007) $797-803$.

[75] J.F. Giarola, K.B. Borges, C.R.T. Tarley, F.M. de Oliveira, E.S. Ribeiro, A.C. Pereira, Development and application of graphite- $\mathrm{SiO}_{2} / \mathrm{Al}_{2} \mathrm{O}_{3} / \mathrm{Nb}_{2} \mathrm{O}_{5}$-methylene blue (GRP-SiAlNb-MB) composite for electrochemical determination of dopamine, Arab. J. Chem. 10 (2017) 430-438. 